\title{
Synthesis and Surface Activity of Some Cationic Gemini Surfactants Containing Aliphatic Spacers
}

\author{
M.K. Zahran, N. A. Negm* and W. A. Mahmoud*** \\ Faculty of Science, Helwan University, "Petrochemicals Department, \\ Egyptian Petroleum Research Institute and ${ }^{* *}$ Egyptian Natural Gas \\ Holding Company, Cairo, Egypt .
}

\begin{abstract}
GOUR CATIONIC Gemini surfactants were synthesized and characterized using different tools. Their surface activities were measured using surface and interfacial tension measurements. The effect of their spacer chain length on the surface activity, emulsification power and interfacial tension was studied. The thermodynamic parameters showed the tendency towards micellization and adsorption. The results showed that longer spacers increased the micellization tendencies of the surfactants, while shorter spacers increased the adsorption propensity at the air-water interface.
\end{abstract}

Keywords: Gemini surfactants, Spacer group, Surface activity and Thermodynamics .

Cationic surfactants consist of a positively charged hydrophilic head group and a hydrophobic tail group. Research on the interfacial properties of monomeric, dimeric and oligomeric ionic surfactants is very important practically, mainly in the petroleum, chemical and pharmaceutical industries ${ }^{(1)}$. A wide range of applications is connected with their adsorption and aggregation properties, high viscosity, detergency, solubilization ability, improvement of wetting, profound antimicrobial activity against bacteria, yeasts, and molds ${ }^{(2-5)}$ and the preparation of micro and meso-porous structures (zeolites); these properties have been the subject of several review articles ${ }^{(6-9)}$. Gemini surfactants are a novel type of surfactant synthesized in the recent years. Its advent has greatly broadened the perspective of interfacial science ${ }^{(10-12)}$. Compared with the conventional surfactants, Gemini surfactants are more efficient in lowering surface tension and have a much lower critical micelle concentration (CMC). Despite their recent development, Gemini surfactants are already a hot subject in colloids and surface science and are considered to be a type of surfactants that will be most widely used in the twenty-first century ${ }^{(13-15)}$. Gemini surfactants are made up of two hydrophilic and two hydrophobic chains covalently linked through a spacer group, which significantly affects their properties ${ }^{(16)}$. All the Gemini surfactants have two important features, namely, much lower critical micelle concentration $(\mathrm{CMC})$ values and highly efficient reduction of the surface tension of water ${ }^{(17)}$. These surfactants have been attracting increasing attention, because their unique properties are superior to those of conventional singlechain (monomeric) surfactants ${ }^{(18-21)}$, but little information is available about

\footnotetext{
* Corresponding author: nabelnegm@hotmail.com
} 
micellization of Gemini surfactants in solutions of different $\mathrm{pH}^{(22,23)}$. In emulsification, as an example, selection of the surfactant or surfactant system will depend on the materials to be used and the properties desired in the end product. During the last few years our laboratory has made extensive efforts to study the use of surfactants in enzymatic and non-enzymatic hydrolysis of carboxylate and phosphate esters ${ }^{(24-28)}$. In this investigation the synthesis and characterization of some diquaternary Gemini surfactants were reported. The effect of the spacer chain length on their surface activity and physicochemical properties was studied in their solution.

\section{Experimental}

\section{Synthesis of 3-aminopyridine Schiff base}

A mixture of 3-aminopyridine ( 0.3 mole, $26.4 \mathrm{~g})$ and benzaldehyde $(0.32$ mole, $33.9 \mathrm{~g})$ was reacted in Dean stark apparatus in presence of xylene (150 $\mathrm{ml}$ ) as a solvent and $p$-toluene sulphonic acid as a dehydrating agent. The reaction was stopped after obtaining the calculated water of the reaction $(0.3$ mole, $5.4 \mathrm{ml}$ ). The reaction mixture was allowed to cool then $100 \mathrm{ml}$ of distilled water is added to the mixture in a separating funnel. Then, the mixture was allowed to separate into two layers, the organic layer contained the product and the unreacted materials and the aqueous layer which contained the catalyst was separated. The solvent was evaporated from the organic layer and vacuum distillation was performed to remove the unreacted benzaldehyde.

\section{Synthesis of quaternary ammonium Gemini surfactants}

A mixture of the obtained Schiff base ( 0.05 mole, $8.8 \mathrm{~g}$ ) and dibromoalkanes (0.025 mole) namely: 1,5-dibromopentane (5.75 g), 1,6-dibromohexane (6.1 g), 1,10-dibromodecane $(7.5 \mathrm{~g})$ and 1,12-dibromdodecane $(8.2 \mathrm{~g})$ was refluxed individually in acetone $(150 \mathrm{ml})$ as a solvent for $12 \mathrm{hr}$. The reaction was allowed to cool overnight to complete precipitation of the products. Then, the reaction mixture was filtered and the product was recrystallized from acetone, washed by diethyl ether and then dried under vacuum for $4 \mathrm{hr}$. The products were analyzed using elemental analysis, FTIR and ${ }^{1} \mathrm{H}-\mathrm{NMR}$ spectroscopy.

\section{Surface and interfacial tension measurements}

Surface and interfacial tension measurements were performed using Krüss K6 tensiometer by the platinum ring detachment method, Germany. Freshly prepared aqueous solutions of the synthesized Gemini surfactants were used with the concentration range of 0.01 to $0.00001 \mathrm{M} / \mathrm{L}$ at $25{ }^{\circ} \mathrm{C}$. The solutions were poured into a clean Teflon cup with a mean diameter of $28 \mathrm{~mm}$ (Teflon cup was used to prevent the adhesion of the surfactant to the glass cup walls). The solutions were left for $2 \mathrm{hr}$ to allow the stabilization and complete adsorption at the solution surface, then the apparent surface tension values were measured for a minimum of 3 times and the recorded values were taken as the average of these values ${ }^{(29)}$. The platinum ring was then removed, washed with diluted $\mathrm{HCl}$ solution and followed by distilled water.

Egypt. J. Chem. 56, No. 1 (2013) 
The interfacial tension measurements were obtained between aqueous solution of the synthesized Gemini cationic surfactants at concentration of $0.1 \%$ by weight and light paraffin oil at $25{ }^{\circ} \mathrm{C}$ using same procedures of the surface tension measurements ${ }^{(30)}$.

\section{Emulsion stability}

Emulsion stability was measured by vigorously stirring a mixture of $10 \mathrm{ml}$ $(0.5 \%)$ of the synthesized cationic surfactant solutions and $10 \mathrm{ml}$ of paraffin oil at $25^{\circ} \mathrm{C}^{(31)}$. Emulsifying power (emulsion stability) of the surfactant solutions was expressed as the time required for separation of $9 \mathrm{ml}$ of pure surfactant solution.

Structure

\section{Results and Discussion}

The chemical structures of the synthesized surfactants were confirmed using elemental analysis, IR and NMR spectra. Table 1 represents the calculated and obtained ratios of the different elements in their chemical structures, which proves their purity.

TABLE 1. Characterization of the synthesized Gemini surfactants .

\begin{tabular}{ccccccccccc}
\hline & $\begin{array}{c}\text { Molecular } \\
\text { Compound }\end{array}$ & \multicolumn{2}{c}{ Carbon \% } & \multicolumn{3}{c}{ Hydrogen \% } & \multicolumn{2}{c}{ Nitrogen \% } & \multicolumn{2}{c}{ Bromine \% } \\
\cline { 3 - 10 } & $\begin{array}{c}\text { MWt, g/mol } \\
\end{array}$ & Calc & Found & Calc & Found & Calc & Found & Calc & Found \\
\hline SB-5 & 594.39 & 58.60 & 58.20 & 5.09 & 5.05 & 9.43 & 9.36 & 26.89 & 26.70 \\
SB-6 & 608.42 & 59.22 & 58.81 & 5.30 & 5.26 & 9.21 & 9.14 & 26.27 & 26.08 \\
SB-10 & 664.53 & 61.45 & 61.02 & 6.07 & 6.02 & 8.43 & 8.37 & 24.05 & 23.88 \\
SB-12 & 692.58 & 62.43 & 62.00 & 6.40 & 6.36 & 8.09 & 8.03 & 23.07 & 22.91 \\
\hline
\end{tabular}

IR spectra showed bands at 3056, 2930, 2860, 1624, 780-920 $\mathrm{cm}^{-1}$.

NMR spectra had the following signals at $\delta(\mathrm{ppm})=1.3\left(\mathrm{CH}_{2}, \mathrm{~m}, \mathrm{nH}\right), 4.5$ $(\mathrm{CH}=\mathrm{N}, \mathrm{s}, 2 \mathrm{H}), 7.3$ (phenyl, m, 18H). That proves the expected chemical structures of the synthesized surfactants as represented in Scheme 1.

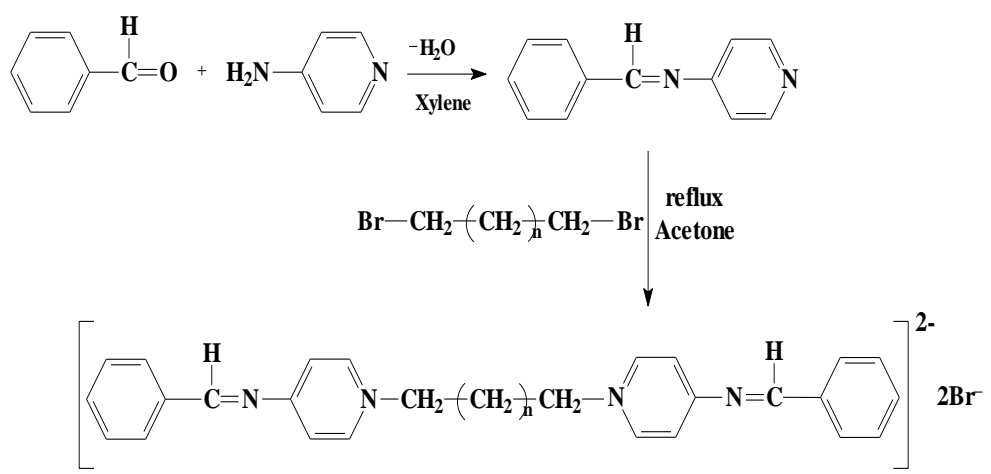

Scheme 1. Synthesis of the Gemini cationic surfactants $(n=3,4,8,10)$. 


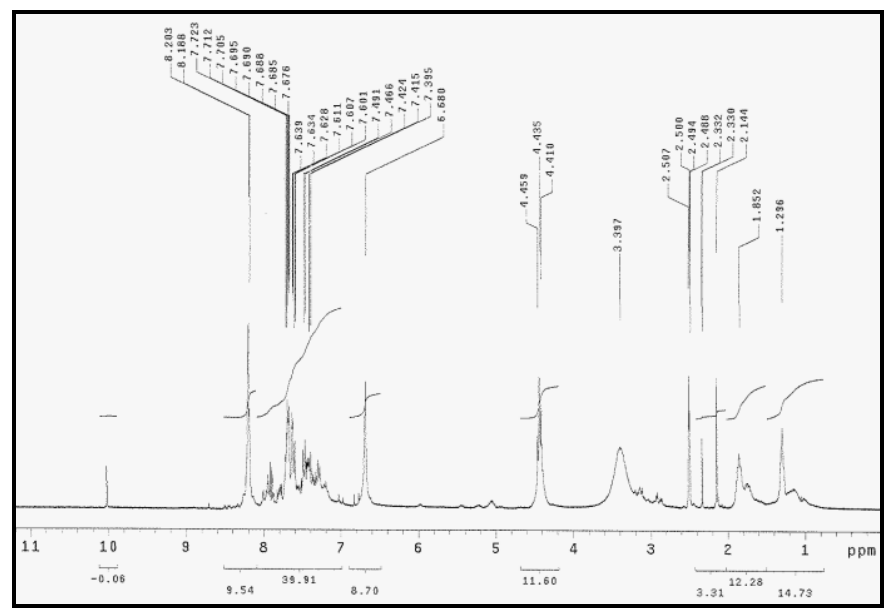

(a)

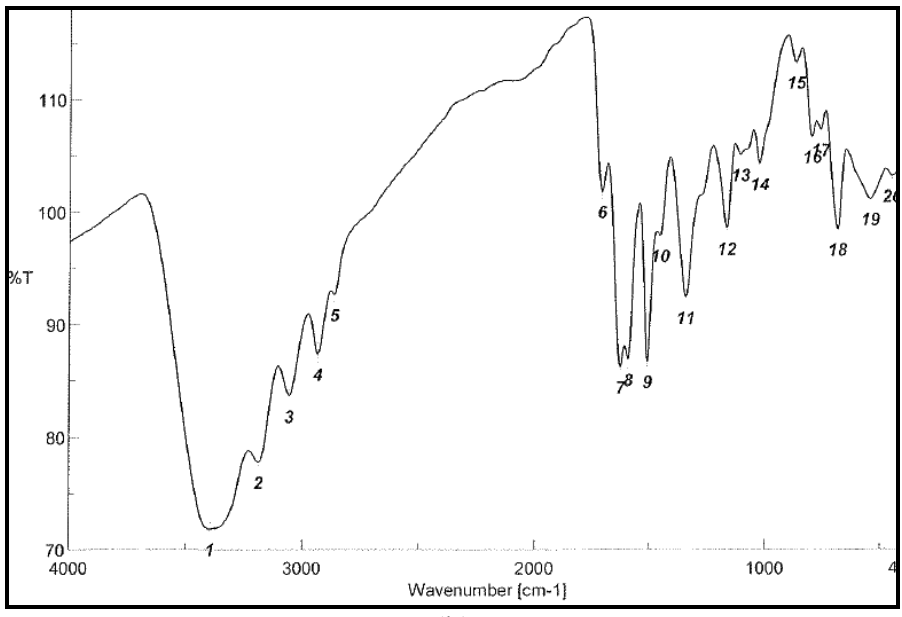

(b)

\section{Surface activity}

Spectral analysis of compound SB-6

The surface tension vs. - log concentration of aqueous solutions of the synthesized Gemini surfactants SB-5, SB-6, SB-10 and SB-12 was measured at $25{ }^{\circ} \mathrm{C}$. The surface tension profile of the different surfactants showed no minimum, which indicates the purity of the surfactants and that there is no contamination in their structures. The minimum appeared mainly in impure or commercial surfactants due to the residual compounds which have higher surface activity than the surfactant under investigation, and appeared in the lower concentration region.

Egypt. J. Chem. 56, No. 1 (2013) 
The obtained surface tension values decreased with increasing the concentration at the lower concentration ranges (pre-micellar region), until reached almost constant values by increasing the concentration (post micellar region) (Fig. 1). The break points of these two regions determined the critical micelle concentration values (CMC) of the surfactants which were listed in Table 2.

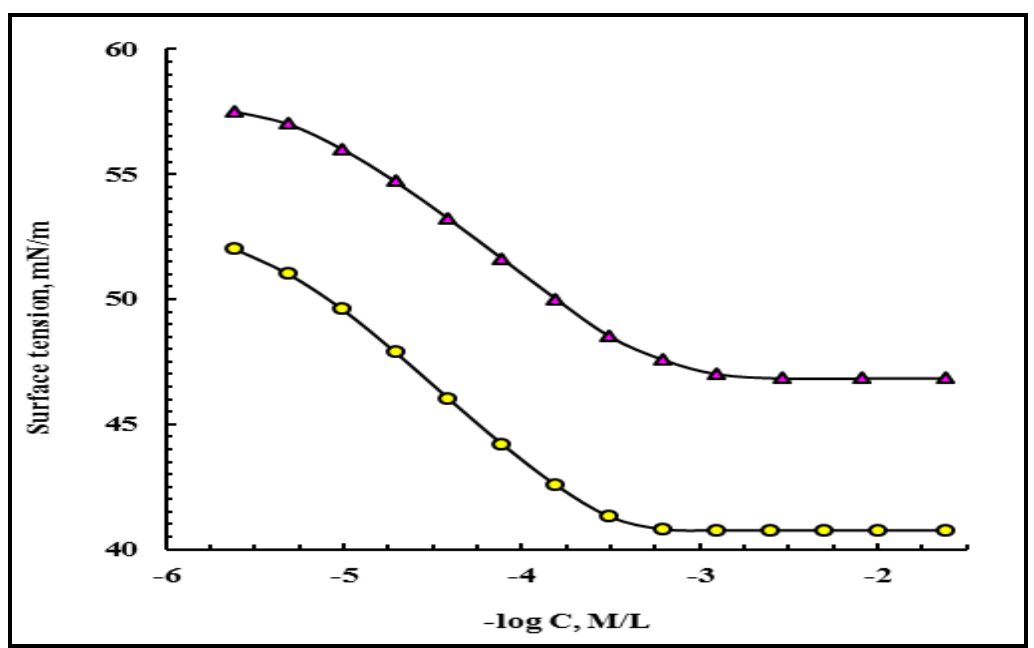

Fig. 1. Surface tension vs. concentration of the synthesized Gemini cationic surfactants $\left(\Delta:\right.$ SB-6, O:SB-12) at $25^{\circ} \mathrm{C}$.

The adsorption of the surfactant molecules at the air-water interface can be interpreted by studying two parameters: the surface pressure and the maximum surface excess $\left(\Gamma_{\max }\right)$. The surface pressure $(\partial \gamma / \partial \log C)$ indicates the pumping of the surfactant molecules to the interface of the solution. Increasing this term revealed that the molecules are adsorbed at the interface more preferably than the lower values ${ }^{(32)}$. It is clear from Table 2 that the increase in the spacer chain length decreases the surface pressure of the surfactant towards the interface.

The maximum surface excess is the maximum concentration of surfactant molecules at the interface of the solution in the saturation case. The maximum surface excess of the synthesized Gemini surfactants was calculated from the slopes of the pre-micellar part $(\partial \gamma / \partial \log C)$ in Fig. 2, according to the Gibb's adsorption equation as follows:

$$
\Gamma_{\max }=(\partial \gamma / \partial \log C) / 2.303 \mathrm{nRT}
$$

where, $\Gamma_{\max }$ is the maximum surface excess at the saturation condition, $\mathrm{n}$ is the number of active species in the solution equal to 3 in case of Gemini surfactants, $\mathrm{R}$ is the gas constant and $\mathrm{T}$ is absolute temperature, the results were listed in Table 2. It is clear from that data in Table 2 that the gradual increase in the spacer chain length decreases the concentration of the surfactant molecules at the interface. 


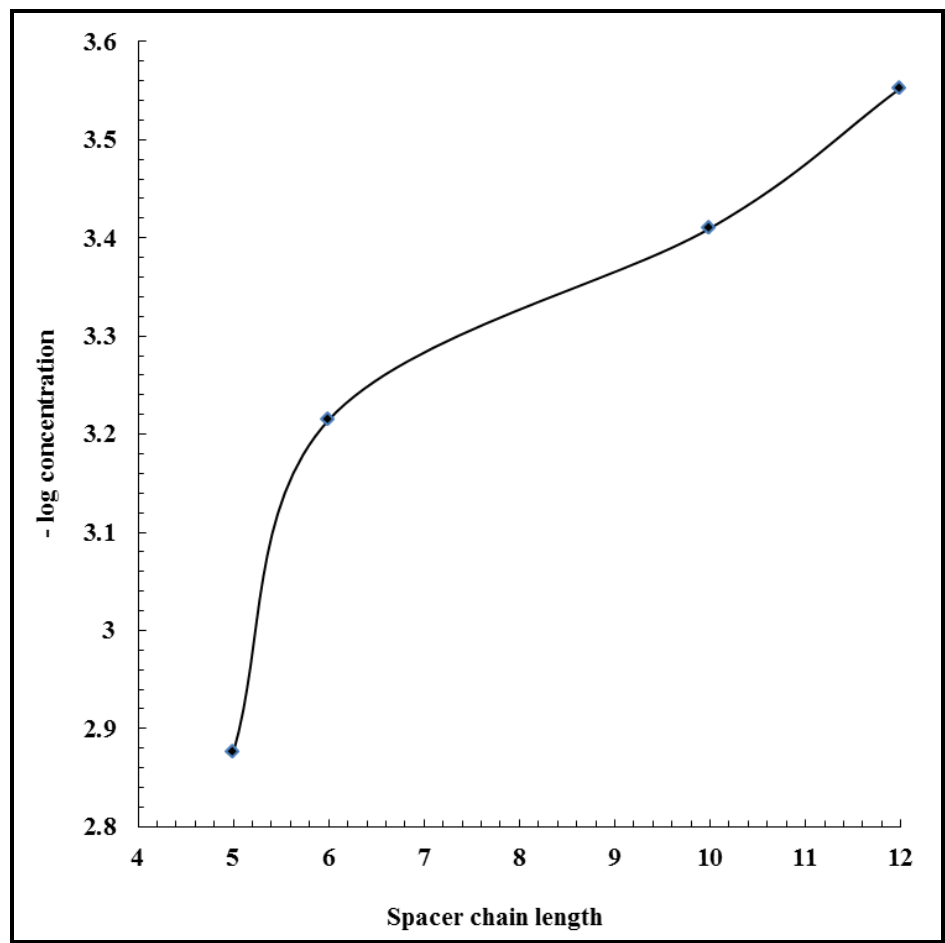

Fig. 2.Effect of spacer chain length on the critical micelle concentration of the synthesized Gemini surfactants at $25^{\circ} \mathrm{C}$.

On the other hand, the average area occupied by the adsorbed surfactant molecules at their solution interface can be calculated using $\Gamma_{\max }$ values as follows:

$$
\mathrm{A}_{\min }=1 /\left(\mathrm{N}_{\mathrm{av}} \cdot \Gamma_{\max }\right)
$$

where, $\mathrm{N}_{\mathrm{av}}$ is Avogadro's number.

The average area at the interface available for each surfactant molecule is increased by increasing the spacer chain length. The maximum area occupied at the interface was $67.4 \mathrm{~nm}^{2}$ obtained for SB-12 surfactant, while the lowest area was $44.6 \mathrm{~nm}^{2}$ for SB-5 surfactant. The obtained values of $A_{\min }$ are larger than the published values of the saturated Gemini surfactant ${ }^{(29)}$. That can be attributed to geometry of the Gemini molecules at the interface. Analysing the data of $\mathrm{A}_{\min }$ in Table 2 showed that the increase in $\mathrm{A}_{\min }$ was $22.8 \mathrm{~nm}^{2}$ by increasing the spacer chain length from 2 to 10 methylene groups. That showed the average value of the individual methylene group is $2.28 \mathrm{~nm}^{2}$ which is in good agreement with our previously published data $\left(2.2 \mathrm{~nm}^{2}\right)^{(12)}$. 
TABLE 2. Surface activities of the Gemini surfactants at $25^{\circ} \mathrm{C}$.

\begin{tabular}{|c|c|c|c|c|c|c|c|c|c|c|c|c|}
\hline Compound & $\begin{array}{l}\text { CMC, } \\
\text { mM }\end{array}$ & $\begin{array}{l}\gamma_{\mathrm{cmc}}, \\
\mathbf{m N m}^{-1}\end{array}$ & $\begin{array}{l}\text { Interfacial tension, } \\
\mathrm{mNm}^{-1}\end{array}$ & $\begin{array}{l}\boldsymbol{\pi}_{\mathrm{cmc}}, \\
\mathbf{m N}^{-1}\end{array}$ & $\begin{array}{l}\mathrm{C}_{20}, \\
\mathbf{X} 10^{6} \mathrm{M}\end{array}$ & $\partial \gamma \partial \log \mathrm{C}$ & $\begin{array}{l}\Gamma_{\max }, \\
\mathbf{X}^{10^{11}}\end{array}$ & $\mathrm{CMC} / \mathrm{C}_{20}$ & $\begin{array}{l}A_{\text {min }} \\
\mathbf{n m}^{2}\end{array}$ & $\begin{array}{l}\text { Emulsification, } \\
\text { Sec }\end{array}$ & $\begin{array}{l}\Delta \mathbf{G}_{\text {mic, }} \\
\text { kJmol }^{-1}\end{array}$ & $\begin{array}{l}\Delta \mathbf{G}_{\text {ads, }} \\
\mathbf{k J m o l}^{-1}\end{array}$ \\
\hline SB-5 & 1.33 & 50 & 15 & 21.8 & 316 & -6.37 & 3.72 & 4.21 & 44.6 & 120 & -16.4 & -22.3 \\
\hline SB-6 & 0.61 & 47 & 13 & 24.8 & 66.8 & -5.03 & 2.94 & 9.13 & 56.5 & 300 & -18.3 & -26.8 \\
\hline SB-10 & 0.39 & 43 & 9 & 29 & 14.8 & -4.01 & 2.71 & 26.35 & $61 . .3$ & Stable & -19.91 & -29.7 \\
\hline SB-12 & 0.28 & 41 & 6 & 30.8 & 3.87 & -4.22 & 2.47 & 72.35 & 67.4 & Stable & -20.3 & -32.7 \\
\hline
\end{tabular}

CMC: critical micelle concentration in $\mathrm{mM}, \boldsymbol{\gamma}_{\mathrm{cmc}}$ : surface tension at CMC, $\boldsymbol{\pi}_{\mathrm{cmc}}$ : effectiveness, $\mathbf{C}_{20}$ : efficiency, $\boldsymbol{\Gamma}_{\text {max }}:$ maximum surface excess, $\partial \gamma / \partial \log \mathbf{C}$ : slope of surface tension vs concentration profile, $\mathbf{C M C} / \mathbf{C}_{2}$ : ratio between $\mathrm{CMC}$ and efficiency, $\mathbf{A}_{\min }$ : minimum surfacearea, $\Delta \mathbf{G}_{\text {mic }}$ : micellization free energy, $\Delta \mathbf{G}_{\text {ads: }}$ : adsorption free energy. 
The chemical structures of the Gemini surfactants play an important role on their surface activity, and mainly on their CMC values. In case of saturated Gemini surfactants, the terminal alkyl chains have a high tendency towards geometrical conformation at the interface ${ }^{(33)}$, which decreases the area occupied by each molecule at that interface. As a result, the surface concentration is increased gradually by increasing the terminal alkyl chain length and also by the gradual increase of the spacer chain length. The increase of surface concentration increases the concentration of surfactant molecules at the interface, and consequently increases their CMC values. Gemini surfactant molecules adopt different conformations depending on the spacer length. Before micellization 12-2-12 monomers are in the trans conformation. While in case of 12-4-12 and 12-6-12, they are in the cis conformation ${ }^{(19)}$. In the case of the trans conformation, the free energy of transfer for the surfactant monomer from the aqueous phase to the pseudo micellar phase is relatively lower as compared to the cis conformation case. Hence, micellization is relatively more easily facilitated for 12-2-12 (lower CMC) and vice versa for 12-4-12 and 12-6-12. In case of the unsaturated or conjugated terminal hydrophobic groups, the geometry of these groups is highly restricted toward conformation and their situation is forced to be planner at the interface. Hence, by increasing the spacer chain length, the area occupied by each molecule at the interface is increased. That decreases the surface concentration of these molecules at the interface, which forced the molecules to micelize at lower concentration than the saturated homologous do.

In case of our synthesized Gemini cationic Schiff bases, the terminal groups are two phenyl groups linked by a double bond (azomethine group) and the spacer groups are varied from 5 to 12 methylene groups (Scheme 1). The geometry of these molecules is forced to be planner at the interface due to the lack of the flexibility of these groups. The rigidity of the structure increased the area of the molecules at the interface and consequently the surface concentration is decreased. The decrease in surface concentration indicates that the interface is completely covered by the adsorbed surfactant molecules. Hence, the molecules undergo to the bulk of their solution to form micelles. The critical micelle concentration of the synthesized surfactants was decreased by increasing the spacer chain length gradually from 5 to 12 methylene groups as represented in Fig. 2.

Surface tension reduction, effectiveness and efficiency $\left(\gamma_{c m c}, \pi_{c m c}, P c_{20}\right)$

The surface tension reduction at the critical micelle concentration of the synthesized surfactants is ranged between 50 and $41 \mathrm{mN} / \mathrm{m}$ (Table 2). That indicates the lower surface activity of these surfactants compared to the saturated cationic Gemini surfactants ${ }^{(34)}$. This can be attributed to the lower surface concentration of the surfactants at the interface and also to the high hydrophobic characters of these molecules ${ }^{(35)}$. The higher surface tension reduction accompanied by longer hydrophobic spacer chain length is attributed

Egypt. J. Chem. 56, No. 1 (2013) 
to the fast interface saturation. That describes the fast adsorption of the surfactant molecules at this interface. SB-5 surfactant has the highest surface tension reduction at $\mathrm{CMC}$, which points out the lower adsorption tendency than the other surfactants.

The effectiveness values $\left(\pi_{\mathrm{cmc}}\right)$ of the prepared surfactants are shown in Table 2, where the efficiency is slightly increased from 21 to $30 \mathrm{mN} / \mathrm{m}$ by increasing the number of methylene groups from 5 to 12 . This is due to the fact that the efficiency of adsorption at interfaces increases linearly with an increase in the carbon atoms of hydrophobic group ${ }^{(36,37)}$. While, the efficiency values $\left(\mathrm{Pc}_{20}\right)$ decreased gradually by increasing the hydrophobic chain length. The efficiency parameter indicates the adsorption behavior of the surfactants at the interface. Higher efficiency values revealed to lower adsorption tendency.

The ratio between CMC and the efficiency determines the tendency of the surfactant molecules towards the micellization and adsorption in the solution. Increasing this value indicates the high tendency towards adsorption than micellization, and vice versa. It is clear from the values of $\mathrm{CMC} / \mathrm{C}_{20}$ listed in Table 2 that the surfactants lean towards adsorption by different tendencies. SB5 has the lowest tendency towards adsorption by four folds than micellization. The highest adsorption tendency was obtained in case of SB-12 by 67 folds than micellization.

\section{Emulsification power and interfacial tension}

The emulsification powers of the synthesized Gemini cationic surfactants were determined as a time required to breakdown the emulsion formed between surfactant solution and paraffin oil. The emulsification of the surfactants is one of the most important surface properties at the interface. The emulsification tendency in some cases is important to form stable emulsions, as in case of solubilization, emulsification processes, cosmetics and drug formulations. While, in some applications it is not favorable especially in case of petroleum applications including demulsification and corrosion inhibition. Table 2 lists the emulsification tendency of the synthesized surfactant in presence of light paraffin oil. It is clear that the emulsification power is completely dependent on the space chain length. Short spacer of two methylene groups has the lowest emulsification tendency at $120 \mathrm{sec}$, while increasing the spacer chain length to six methylene groups considerably increases the emulsification power to $300 \mathrm{sec}$. The longest spacer of twelve methylene groups produces stable oil/solution emulsion even after 30 days. The results can be easily related to the depression at surface tension and the saturation concentration of these surfactants at the air-solution interface.

On the other hand, the interfacial tension is related to the saturation of the surfactant molecules at the interface. The data in Table 2 revealed that the interfacial tension of the surfactants under consideration is decreased by increasing the spacer chain length, and the lowest interfacial tension was obtained in presence of the longest spacer chain of this series. 
Thermodynamics of adsorption and micellization

The thermodynamic data of adsorption and micellization of the synthesized surfactant were calculated according to the following equations, where $\mathrm{n}$ is equal to the number of the ionic species in the solution $=3^{(9)}$ :

$$
\begin{gathered}
\Delta \mathrm{G}_{\text {mic }}=2.303 n R T(\log \mathrm{CMC}) \\
\Delta \mathrm{G}_{\mathrm{ads}}=\Delta \mathrm{G}_{\text {mic }}-\left(0.6 \mathrm{x} \pi_{\mathrm{cmc}} \times \mathrm{A}_{\text {min }}\right)
\end{gathered}
$$

The listed values in Table 2 revealed that the two processes of adsorption and micellization occurred spontaneously with more preference towards adsorption than micellization. That was indicated by the more negative values of the adsorption free energy than the micellization. Furthermore, SB-12 showed high difference between the adsorption and micellization free energies, with more negativity in adsorption free energy. That showed the stability of the adsorption monolayer of SB-12 at the interface than their presence in the bulk in forms of micelles.

\section{References}

1. Cross, J. and Singer, E.J., Cationic Surfactants: Analytical and Biological Evaluation. Marcel Dekker, New York (1994).

2. Han, L., Ye, Z., Chen, H. and Luo, P., The interfacial tension between cationic Gemini surfactant solution and crude oil. J. Surf Deterg. 12,185-190 (2009).

3. Sharma, K.S., Patil, S.R., Rakshit, A.K., Glenn, K., Doiron, M., Palepu, R.M. and Hassan, P.A., Self-aggregation of a cationic-nonionic surfactant mixture in aqueous media: tensiometric, conductometric, density, light scattering, potentiometric and fluorimetric studies. J. Phys.Chem. B 108, 12804-12812 (2004) .

4. Lu, T., Li., Z., Huang, J. and Fu, H., Aqueous surfactant two-phase systems in a mixture of cationic Gemini and anionic surfactants. Langmuir, 24,10723-10728 (2008).

5. Prez, L., Pinazo, A., Infante, M.R. and Pons, R., Investigation of the micellization process of single and Gemini surfactants from arginine by SAXS, NMR selfdiffusion, and light scattering. J. Phys.Chem. B 111, 11379-11387(2007) .

6. Souguir, Z., Roudesli, S., About-Jaudet, E., Picton, L. and Cerf, D.L., Novel cationic and amphiphilic pollutant derivatives II: pH dependant physicochemical properties. Carbohydrate Polym, 80, 123-129 (2010) .

7. Rosen, M.J., Surfactants and Interfacial Phenomena: $2^{\text {nd }}$ ed. Wiley, New York (1988).

8. Das, D., Roy, S., Mitra, R.N., Dasgupta, A. and Das P.K., Headgroup size or hydrophilicity of surfactants: the major regulator of lipase activity in cationic waterin-oil microemulsions. Chem. Eur. J. 11, 4881-4889 (2005).

9. Zana, R., Dimeric (Gemini) surfactants: effect of the spacer group on the association behavior in aqueous solution. J. Colloids Interface Sci. 248, 203-220 (2002) .

Egypt. J. Chem. 56, No. 1 (2013) 
10. Menger, F.M. and Littau, C.A., Gemini surfactants: synthesis and properties. $J$. Am. Chem. Soc. 113, 1451-1452 (1991).

11. Menger, F.M. and Littau, C.A., Gemini surfactants: a new class of self-assembling molecules. J. Am. Chem. Soc. 115, 10083-10090 (1993) .

12. Menger, F.M. and Keiper, J.S., Gemini Surfactant. Angew ChemInt, Ed. 39, 1906 $1920(2000)$.

13. Zhigang, Y., Ganzuo, Li., Dong Hu and Aixi, F., Progress in synthesis in Gemini surfactants. Prog Chem. 16, 349-364 (2004) .

14. Rosen, M.J., Geminis: a new generation of surfactants. Chem. Tech. 23, 30-32 (1993) .

15. Zana, R., Gemini (dimeric) surfactants. CurrOpin Colloid Interface Sci. 1, 566-571 (1996) .

16. Khan, I.A., Mohammad, R., Alam, M.S., Kabir-ud-Din, Surface properties and mixed micellization of cationic Gemini surfactants with ethyleneamines. J. Chem. Eng Data, 55, 370-380 (2010)

17. Zana, R., Levy, H., Danino, D., Talman, Y. and Kwetkat, K., Micellization of cetyltrimethylammonium bromide and an anionic dimeric (Gemini) surfactant in aqueous solution. Langmuir, 13, 402-408 (1997)

18. Esumi, K., Taguma, K. and Koide, Y., Aqueous properties of multichain quaternary cationic surfactants. Langmuir, 12, 4039- 4041 (1996) .

19. Jungermann, E., Cationic Surfactants. Marcel Dekker, New York (1970) .

20. Richmond, J.M., Cationic Surfactants: Organic Chemistry. Marcel Dekker, New York (1990) .

21. Rubingh, D.N. and Holland, P.M., Cationic Surfactants: Physical Chemistry. Marcel Dekker, New York (1991).

22. Chakraborty, T. and Ghosh, S., Mixed micellization of an anionic Gemini surfactant (GA) with conventional polyethoxylated nonionic surfactants in brine solution at pH 5 and 298 K. Colloid Polym. Sci. 285, 1665-1673 (2007).

23. Ghosh, S. and Chakraborty, T., Mixed micelle formation among anionic Gemini surfactant (212) and its monomer (SDMA) with conventional surfactants (C12E5 and C12E8) in brine solution at pH 11. J. Phys.Chem. B 111, 8080 (2007).

24. Ghosh, K.K. and Verma, S.K., Kinetics of enzyme catalyzed hydrolysis of 4nitrophenyl acetate in ethanolamine surfactants. Indian J. Biochem. Biophys. 45, 350-353(2008) .

25. Ghosh, K.K. and Verma, S.K., Effect of head group of cationic surfactants on the hydrolysis of p-nitrophenyl acetate catalyzed by a-chymotrypsin. Int. J. Chem. Kinetics, 41, 377-381 (2009) . 
26. Tiwari, S., Ghosh, K.K., Marek, J. and Kuca, K., Functionalized surfactant mediated reactions of carboxylate, phosphate and sulphonate esters. J. Phys. Org. Chem. 23, 519-525 (2010) .

27. Tiwari, S., Ghosh, K.K., Marek, J. and Kuca, K., Spectrophotometric determination of the acidity constants of some oximebased a-nucleophiles. J. Chem. Eng. Data, 55, 1153-1157 (2009) .

28. Ghosh, K.K., Sinha, D., Satnami, M.L., Dubey, D.K., Dafonte, P.R. and Mundhara, G.L., Nucleophilicdephosphorylation of p-nitrophenyldiphenyl phosphate in cationic micellar media. Langmuir, 21, 8664-8669 (2005) .

29. Chavda, S., Bahadur, P. and Aswal, V.K., Interaction between nonionic and Gemini (cationic) surfactants: effect of spacer chain length. J. Surfact. Deterg . 14, 353-362 (2011).

30. Anoune, N., Nouiri, M., Arnaud, C., Petit, S. and Lanteri, P., Synthesis and characterization of new cationic surfactants derived from lactic acid. J. Surfact. Deterg. 3, 381-386 (2000).

31. Negm, N.A. and Mohamed, A.S., Surface and thermodynamic properties of diquaternary bola-form amphiphiles containing aromatic spacer. J. Surfact. Deterg. 7, 23-30 (2004).

32. Abdel-Salam, F.H. and El-Said A.G., Synthesis and surface active properties of Gemini cationic surfactants and interaction with anionic azo dye (AR52). J. Surfact. Deterg. 14, 371-379 (2011).

33. Wang, X., Wang, J., Wang, Y., Ye, J., Yan, H. and Thomas, R.K., Properties of mixed micelles of cationic Gemini surfactants and nonionic surfactant PEG-TMBPE: effects of the surfactant composition and the spacer length. J. Colloid. Interface. Sci. 286, 739-746 (2005).

34. Kim, T.S., Kida, T., Nakatsuji, Y. and Ikeda, I., Surface-active properties of novel cationic surfactants with two alkyl chains and two ammonium groups. J. Am. Oil Chem. Soc. 73, 907-911 (1996).

35. Rosen, M.J., Surfactants and Interfacial Phenomena, $3^{\text {rd }}$ ed, Wiley, New York, p. 127-129 (2005) .

36. Tatsumi, T., Zhang, W., Kida, T., Nakatsuji, Y., Ono, D., Takeda, T. and Ikeda, I., Novel hydrolyzable and biodegradable cationic Gemini surfactants: 1, 3-Bis [(acyloxyalkyl) -dimethylammonio] -2-hydroxy propane dichloride. J. Surfact. Deterg. 2,167-172 (2000).

37. Andrzej, P., Beata, W., Jacek, L., Dorota, P., Stanislaw, W. and Anna, K., Bifunctional N-oxides of alkyldiamidoamines. J. Surfact. Deterg. 12, 201-207 (2009).

(Received 25/3/2013; accepted 28/3/2013)

Egypt. J. Chem. 56, No. 1 (2013) 
